\title{
DIMENSIONAMENTO DE SISTEMAS DE IRRIGAÇÃO POR GOTEJAMENTO
}

\author{
DIMENSIONING OF IRRIGATION SYSTEMS BY DRIPPING
}

Felipe Castelani ${ }^{1}$

Romulo Nava Moreira ${ }^{2}$

\section{RESUMO}

A redução de custos na produção agrícola vem sendo considerada um dos fatores mais importantes para que este ramo se torne viável e lucrativo, pois cada vez mais se busca maior produção em menor área cultivada. A irrigação é uma ferramenta considerada indispensável para produção de alimentos, e se não empregada de forma correta resulta em desperdícios dos recursos naturais disponíveis e consumo desnecessário de energia. Portanto faz-se de suma importância o dimensionamento correto, para tornar viável e mais eficiente. O sistema de irrigação por gotejamento apresenta uma série de vantagens à agricultura, a natureza e a humanidade, trazendo um uso mais consciente de água, reduzindo as aplicações de agrotóxicos resultando em um alimento mais saudável e mais barato.

Palavras-Chave: Irrigação, gotejamento, dimensionamento, redução de custos.

\section{ABSTRACT}

The reduction of costs in agricultural production has been considered one of the most important factors for this branch to become viable and profitable, as more and more is sought in smaller cultivated area. Irrigation is a tool considered indispensable for food production, and if not used correctly results in waste of available natural resources and unnecessary consumption of energy. Therefore, the correct sizing is done to make it viable and more efficient. The drip irrigation system has a number of advantages to agriculture, nature and mankind, bringing a more conscious use of

1 Graduado em Engenharia Mecânica, pela Universidade Alto Vale do Rio do Peixe (UNIARP). E-mail: felipecastelani@hotmail.com.

2 Orientador. Graduado em Engenharia de Controle e Automação pela Universidade do Contestado (UNC). Especialização em Automação Industrial pela Unidade de Ensino Superior Vale do Iguaçu (UNIGUAÇU), docente na Universidade Alto Vale do Rio do Peixe (UNIARP) 
water, reducing the applications of pesticides resulting in a healthier and cheaper food.

Keywords: Irrigation, dripping, sizing, cost reduction.

\section{INTRODUÇÃO}

O sistema de irrigação por gotejamento traz inúmeras vantagens significativas, tais como, menor uso de água, transporte de nutrientes, transporte de substâncias químicas, menor demanda de mão de obra, ações corretivas em curto prazo, aumento significativo da sustentabilidade da plantação, consequentemente uma maior produtividade resultando em lucros, entretanto essas vantagens tornamse limitadas e de certa forma ineficazes se os processos de execução de montagem, e escolha correta dos componentes não atenderem as exigências admissíveis e adequadas para se elaborar um projeto com total eficiência e o melhor resultado.

Segundo Frizzone (2017) a agricultura irrigada aumenta nas mais diversas condições de meio físico, consentindo a uma grande abundância de culturas e de interesses sociais e econômicos, de forma que não é possível haver um exclusivo sistema de irrigação ideal, apropriado a atender do melhor caráter a todas as condições e fins envolvidos. Em decorrência, deve-se escolher o sistema de irrigação mais apropriado a cada condição em particular, analisando-se os interesses envolvidos.

Sabendo da importância da irrigação na agricultura e principalmente no agronegócio para uma produção adequada, logo este trabalho surgiu como propósito de melhorar o sistema de irrigação convencional com redução de custos e melhor aproveitamento dos recursos naturais disponíveis, sendo indispensável e de suma importância o uso da engenharia para chegar-se a um projeto com total funcionalidade, onde o uso de sistemas de irrigação por gotejamento pode ser considerada a melhor alternativa.

Para a escolha correta dos componentes, exige-se conhecimento no campo da hidráulica, tais como cálculos de vazão, pressão, perda de carga entre outros que serão indispensáveis para a elaboração deste projeto.

Dentro deste contexto surge o seguinte problema: Como produzir um sistema de irrigação artificial no agronegócio? 
Devido tais motivos, o objetivo geral deste trabalho é dimensionar um sistema de irrigação por bombeamento e gotejamento para uma área referente a um hectare com a cultivar de tomate.

\section{MATERIAIS E CARACTERÍSTICAS DO SISTEMA}

Antes de iniciar o dimensionamento do sistema de irrigação definiu-se na utilização da tubulação principal de recalque e bomba disponíveis. Após a análise do terreno, foi desenvolvido um breve desenho do sistema de irrigação. O croqui possui como finalidade promover o entrosamento ao projeto, facilitando assim o entendimento proposto deste trabalho.

A área a ser irrigada possui dimensões de $100 \times 100$ m, assim totalizando $10000 \mathrm{~m}^{2}$. Também pode se visualizar as linhas com as fitas gotejadoras, sendo elas 62 linhas com comprimento de $100 \mathrm{~m}$ totalizando $6200 \mathrm{~m}$ linear de fita gotejadora. Também será utilizado tubulação de pvc de 3" desde a bomba e na linha de principal ligada por meio de um tê de $90^{\circ}$ saída lateral. Na linha principal é necessário a utilização de 9 Tês de 3 " com saída lateral de 3/4, que será ligado um tubo de polietileno. As fitas gotejadoras serão conectadas neste tubo de $3 / 4$ através de conetores com rosca.

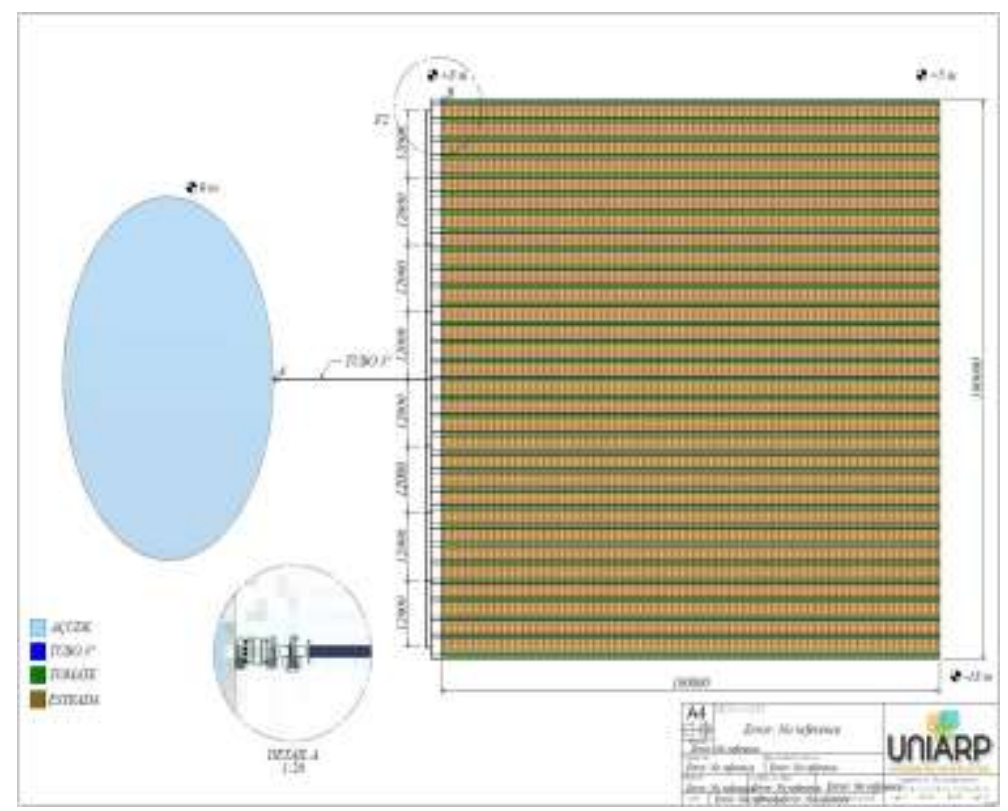

Figura 1 - Croqui preliminar do sistema de irrigação 
Devido a facilidade de ser encontrada no mercado, fita gotejadora utilizada no dimensionamento é do modelo Amanco Drip $8 \mathrm{MIL}$, com espaçamento de $30 \mathrm{~cm}$ entre gotejadores conforme Anexo 2 e diâmetro de 16,1 mm, que opera com pressão de 1 BAR, conforme Anexo 1. A pressão em que a mesma opera é considerada baixa, o que torna viável para a prática do projeto com alta eficiência. Além de operar com baixa pressão, outro fator analisado é a vazão de $0,0016 \mathrm{~m}^{3} / \mathrm{ou}$ 1,6 I/h por gotejador como mostra no Anexo 1.

Sabendo que cada fita gotejadora corresponde a $100 \mathrm{~m}$, teremos em torno de 333,3 gotejadores com vazão de $0,533 \mathrm{~m}^{3} / \mathrm{h}$ por linha, portanto basta multiplicarmos pela quantidade de linhas que é 62 e teremos a vazão total da área irrigada, representando $33,03 \mathrm{~m}^{3} / \mathrm{h}$.

\section{DIMENSIONAMENTO}

Nesta etapa realizou-se o dimensionamento da tubulação utilizada. O tubo de sucção é de matéria plástica do tipo mangote com diâmetro de 4" com comprimento total de $4 \mathrm{~m}$, a bomba está a uma altura de $1 \mathrm{~m}$ do nível da água do reservatório.

A válvula utilizada é tipo de pé de fero fundido com diâmetro de 4 polegadas. A perda de carga dada na válvula de suç̧ão da bomba é expressa por tabela.

A perda de carga na válvula é igual a 28,6 m equivalentes, conforme Anexo 3. Para calcular a perda de carga utiliza-se a Equação 7 , onde o comprimento $l=4 \mathrm{~m}$ soma-se com a perda de carga da válvula que é 28,6 m equivalentes e a gravidade, $g=10$. Após o resultado soma-se o valor da altura da bomba em relação ao nível do reservatório. Calcula-se a perda de carga no ponto mais crítico do sistema, onde o desnível está em $8 \mathrm{~m}$ acima do nível da água do reservatório. Para calcular a perda de carga na tubulação de recalque, divide-se em etapas e tento a última etapa calculada soma-se todas as perdas, inclusive a perda de carga na tubulação de sucção e a pressão de trabalho da fita gotejadora.

Na saída da bomba está localizada um registro de gaveta que possui perda de carga $\mathrm{hf}=0,9 \mathrm{~m}$ equivalentes, conforme Anexo 3. A tubulação possui comprimento $\mathrm{I}=30 \mathrm{~m}$ até no Tê de saída bilateral e $\mathrm{I}=50 \mathrm{~m}$ para cada lado do mesmo 
com diâmetro 3" assim como o registro. Do Tê 90 de saída bilateral com diâmetro 3" ate a primeira saída com diâmetro 3/4". O Tê de saída bilateral possui perda de carga de $8 \mathrm{~m}$ equivalentes, conforme Anexo 4, o comprimento I=12 m. Também neste ponto a vazão passa a ser $Q=14,8 \mathrm{~m}^{3} / \mathrm{s}$, pois a mesma esta sendo divida ao meio. Da primeira saída $3 / 4$ " até a segunda, a vazão passa a ser $Q=11,1 \mathrm{~m}^{3} / \mathrm{h}$. Da segunda saída $3 / 4$ " até a terceira a vazão passa a ser $Q=7,4 \mathrm{~m}^{3} / \mathrm{h}$. Da terceira saída $3 / 4$ " até a quarta a vazão passa a $\operatorname{ser} Q=3,7 \mathrm{~m}^{3} / \mathrm{h}$. Da quarta saída até a primeira fita gotejadora, a vazão será $Q=3,7 \mathrm{~m}^{3} / \mathrm{h}$, e o diâmetro do tubo é $3 / 4$ " ou $0,019 \mathrm{~mm}$. Sabendo o fator de friç̧ão e a velocidade da água no tubo $V=3,6 \mathrm{~m} / \mathrm{s}$, calcula-se a perda de carga através da Equação 7, onde soma-se a perda de carga do Tê de saída bilateral com diâmetro de 3/4", 2,4 m equivalente, conforme Anexo 4 ao comprimento comprimento do tubo.

Após calcular as perdas de carga em todas as etapas, soma-se com o desnível, este sendo $8 \mathrm{~m}$ e a pressão de trabalho de trabalho da fita gotejadora sendo de $1 \mathrm{Bar}$, equivalente a $10 \mathrm{mca}$. A soma de todas as perdas de carga na tubulação de recalque totaliza $\mathrm{hf}=5,23 \mathrm{mca}$. A perda de carga no tubo de sucção apresenta um total de $\mathrm{hf}=1,37 \mathrm{mca}$. O total de perda de carga no sistema para o ponto mais critico é $\mathrm{hf}=24,6 \mathrm{mca}$. Portanto o ponto de trabalho final será de $33,03 \mathrm{~m}^{3} / \mathrm{h} @ 24,6$ mca.

Logo obtido todas as perdas de carga faz-se a análise da bomba. Etapa em verifica-se se a bomba disponível na propriedade atende aos requisitos do sistema. De acordo com o Anexo 5, a bomba atende ao trabalho requerido pelo sistema.

Foi realizado o orçamento em uma loja especializada, dos componentes necessário para a montagem do sistema de irrigação, conforme Anexo 6, totalizando $\mathrm{R} \$$ 3.217,85. O valor de mercado da bomba Triglau BTI 2, utilizado neste dimensionamento é em torno de $\mathrm{R} \$ 2.000,00$. O custo total para a montagem do sistema irrigação por gotejamento foi de $\mathrm{R} \$ 5.217,85$. 


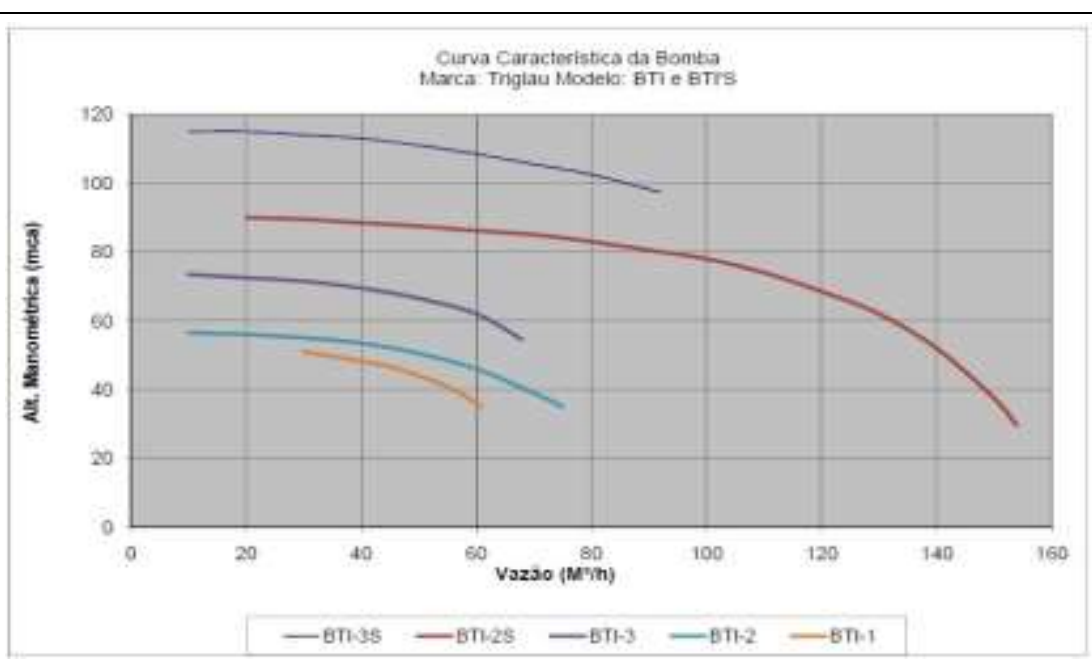

Figura 2 - Curva de Característica da Bomba

\section{RESULTADOS E DISCUSSÃO}

O sistema de irrigação dimensionado teve por finalidade comprovar que é possível obter uma irrigação de baixo custo com excelente funcionalidade, tendo como princípio a importância da irrigação na agricultura. No sistema dimensionado optou-se na utilização dos principais equipamentos necessários, sendo a bomba centrífuga e tubulação principal de recalque, já disponíveis na propriedade a fins de menores gastos e redução de custos. O sistema tem como característica a disponibilidade de água apenas no sistema radicular da planta na medida correta, tendo como resultado um sistema de baixa vazão.

Inicialmente foi elaborada uma análise do terreno a ser irrigado, para definir sua dimensão, sendo de $10000 \mathrm{~m}^{2}$ referente a um hectare, e os possíveis desníveis, onde se constatou o ponto mais crítico do sistema, com 8 metros acima do nível do lago a ser captado a água, sendo que foi elaborado os cálculos com base neste ponto.

O primeiro ponto calculado a perda de carga foi no tubo e sucção da bomba, ou mangote, onde se obteve a perda de carga de 1,37 metros de coluna de d'água, já somada com a perda de carga equivalente da válvula de sucção localizada na ponta do mangote, obtida através de tabela de perda de carga de acessórios.

O segundo ponto é da saída da bomba até o Tê de saída bilateral, localizado na tubulação lateral. A perda de carga obtida foi de 1,5 metros de coluna d'água. 
Neste ponto somou-se a parda de carga equivalente do registro de gaveta, localizado na saída da bomba, o valor foi obtido na tabela de perda de carga em acessórios.

A terceira etapa calculada foi do Tê de saída bilateral até a primeira saída com diâmetro de $3 / 4 "$, seguindo o sentido mais alto da lavoura. O comprimento da tubulação neste e nos próximos passos é 12 metros, o qual será somado com a perda equivalente de cada acessório localizado dentro dessa distância. Neste ponto foi utilizado apenas a metade da vazão total do sistema. A perda de carga obtida neste ponto foi de 0,21 metros de coluna d'água. Foi necessário somar a perda de carga equivalente do Tê de $90^{\circ}$ com saída bilateral, cuja foi obtida através da tabela de perda de carga de acessórios de pvc.

Foi utilizado como princípio para os cálculos a vazão. A vazão passa a diminuir de acordo com que se efetuam os pontos dimensionados, pois parte desta vazão passa a ser consumida pelas saídas anteriores que já foram calculadas. A quarta etapa calculada foi da primeira saída de diâmetro $3 / 4$ " até a segunda, onde a vazão foi de $11,1 \mathrm{~m}^{3} / \mathrm{h}$. A perda de carga neste ponto foi de 0,089 metros de coluna d'água. Para a obtenção deste resultado foi somada a perda de carga e metros equivalentes do Tê de passagem direta, obtido na tabela de perdas de carga em acessórios.

A quinta etapa calcula foi da segunda saída até a terceira saída de $3 / 4 "$. Neste ponto a perda de carga obtida foi de 0,04 metros de coluna d'água. Neste ponto foi somado a perda de carga do Tê, disponível na tabela de perda de carga em acessórios de pvc.

A sexta etapa calculada foi terceira saída até a quarta saída de $3 / 4$ ". Com a vazão bastante reduzida, sendo de apenas $3,7 \mathrm{~m}^{3} / \mathrm{h}$, que é a vazão de cada uma das nove saídas para a tubulação de $3 / 4$ ", a perda de carga também foi menor, sendo esta de 0,013 metros de coluna d'água. Nesta etapa também foi utilizada a perda de carga localizada equivalente do Tê de passagem direta, localizado dentro deste ponto.

A última etapa calculada foi da quarta e última saída 3/4" até a primeira fita gotejadora. Neste ponto a perda de carga obtida foi de 4,75 metros de coluna d'água. Neste ponto a perda de carga foi maior que nos demais, isto devido ao fato da tubulação diminuir seu diâmetro. Neste ponto o comprimento do tubo foi de apenas 2,1 metros com diâmetro de 3/4", que foi somado a perda de carga 
equivalente do Tê de saída bilateral obtida em tabela. Após todos os cálculos realizados efetuou-se a soma de todas as perdas de carga, incluindo a altura do ponto mais crítico e a pressão de trabalho da fita gotejadora, totalizando 24,6 metros de coluna d'água. Com o total de perda de carga juntamente com a curva de característica da bomba, foi possível verificar que a bomba escolhida atende ao trabalho requerido pelo sistema de irrigação, sendo este de 33,03 m³/h @ (entre) 24,6 mca.

O custo dos componentes, como tubos, fita gotejadora, bomba e acessórios necessários para a execução do sistema foi de $R \$ 5.217,85$, valor este considerado baixo.

\section{CONCLUSÕES}

Este trabalho de conclusão de curso foi elaborado com o propósito de dimensionar um sistema de irrigação por gotejamento para a cultura do tomate e apresentar os custos envolvidos na instalação.

Como de início se deu a realização de uma breve introdução ao trabalho, cuja foi abordado o tema da pesquisa e apresentando o problema, posteriormente sua justificativa, o objetivo geral e os objetivos específicos. Posteriormente levantou-se o referencial teórico a respeito dos sistemas de irrigação disponíveis e mais utilizadas na atualidade e do proposto pela pesquisa, coletas de dados necessários para elaboração da metodologia e levantamento de custos.

Nesta etapa foi desenvolvida uma pesquisa técnica e informacional para se obter as informações necessárias, a fim de determinar quais os materiais melhores se adequarão ao sistema de irrigação por gotejamento e definir os métodos de dimensionamento a ser utilizado.

Após feito a análise informacional, optou-se na utilização de alguns materiais e equipamentos já disponíveis na propriedade, a fins de redução de custos e baratear a instalação, onde estes seriam a bomba e a tubulação principal de recalque. Também se definiu que seria utilizada a fita gotejada da marca Amanco, devido à facilidade de ser encontrada no mercado.

No dimensionamento definiu-se que a melhor maneira, seria calcular o caminho que a água percorreria até alcançar o ponto mais crítico da área a ser 
irrigada, cuja esta encontra em maior altura manométrica em relação aos demais pontos, já tendo como base para realização dos cálculos a pressão de trabalho e vazão total do sistema, obtidos em catálogo da fita gotejadora.

Com o dimensionamento realizado foi possível constatar que a bomba disponível na propriedade atende ao trabalho solicitado pelo sistema de irrigação proposto, tendo em vista a extrema eficiência e redução de custos obtidos pelo sistema de irrigação por gotejamento.

\section{REFERÊNCIAS}

FRIZZONE, José Antônio. OS MÉTODOS DE IRRIGAÇÃO. ESALQ/USP. 2017. Disponível em:

<http://www.esalq.usp.br/departamentos/leb/disciplinas/Frizzone/LEB_1571/TEXT O_COMPLEMENTAR_1_METODOS_DE_IRRIGACAO.pdf> Acesso em: 17 ago. 2017>. 